
\title{
26 Research Square \\ COVID-19: Impact of early decision and type of lockdown over the spread of the virus
}

Jehan Al Humaid ( $\nabla$ jaalhumaid@iau.edu.sa )

Imam Abdulrahman Bin Faisal University College of Dentistry

Soban Qadir Khan

Imam Abdulrahman Bin Faisal University College of Dentistry

Faraz Ahmed Farooqi

Imam Abdulrahman Bin Faisal University College of Dentistry

Muhanad Alhareky

Imam Abdulrahman Bin Faisal University College of Dentistry

Faisal Alonaizan

Imam Abdulrahman Bin Faisal University College of Dentistry

Fahad Al Harbi

Imam Abdulrahman Bin Faisal University College of Dentistry

Research article

Keywords: COVID-19, Corona virus, n-CoV

Posted Date: May 22nd, 2020

DOI: https://doi.org/10.21203/rs.3.rs-26573/v1

License: (c) (i) This work is licensed under a Creative Commons Attribution 4.0 International License.

Read Full License 


\section{Abstract}

Objectives: Aim of the present study was to analyze the (1) partial vs complete lock down effects over the spread of COVID-19, (2) time taken for complete lock down decision in relation with the spread of disease.

Method: COVID-19 data for the current observational study was taken up to $14^{\text {th }}$ April since the outbreak of the virus. There were 28 countries which passed through the inclusion criteria and included for analysis.

Results: Average number of reported cases during $1^{\text {st }}, 2^{\text {nd }}$ and $3^{\text {rd }}$ week of lockdown (complete vs partial) were 6872.9 vs 8990,13431 vs 20032 and 19005 vs 26859.5 respectively. However, differences were not statistically significant. Days taken to announce complete lockdown was found significantly correlated with number of cases reported during $1^{\text {st }}$ and $2^{\text {nd }}$ after lockdown announced. Similarly, number of reported cases when lockdown announced had direct and strong correlation with number of weekly reported cases after lockdown.

Conclusion: Number of weekly reported cases among partially lockdown countries was found higher compare to complete lockdown countries. Furthermore, early decision of lockdown was extremely important as it had grave impact over the spread of disease.

\section{Introduction}

Novel Coronaviruses ( $\mathrm{n}-\mathrm{CoV}$ ) commonly referred to as corona virus disease 2019 (COVID-19) belongs to the family of corona viruses that includes the Middle East Respiratory Syndrome (MERS-CoV) and Severe Acute Respiratory Syndrome (SARS-CoV) [1]. The recent outbreak of COVID-19 was initially reported in Wuhan, China. Currently, the virus has spread in over 210 territories and countries. The total number of confirmed COVID-19 cases has increased over 1.8 million. While, the reported number of deaths associated with COVID-19 is over 117,000 according to CDC's situation report 85 [2].

Signs and symptoms of n-CoV infection include respiratory symptoms, fever, cough, shortness of breath and breathing difficulties that could worsen leading to pneumonia, severe acute respiratory syndrome, kidney failure and death. Elderly people are generally more prone to get infected from the corona virus as a result of systemic diseases such as diabetes, lung disease etc. coupled with weak immunity [3]. That is why death rate is highest among elderly population who got infected from the COVID-19 [4].

Standard recommendations in preventing the spread of infection include regular hand washing, covering mouth and nose when coughing or sneezing and avoiding close contact with anyone showing symptoms of respiratory illness such as coughing and sneezing. The $n-C o V$ can survive on surfaces for a few hours or up to several days depending on the various factors like type of surface, temperature or humidity of the environment [5]. 
Based on world health organization (WHO) data, progression in the number of reported cases and percentage death toll differs in various countries [6]. Based on statistics high death toll is reported in some European countries as well as in USA. A large number of positive cases have been reported in these countries. Various steps have been adapted by different countries in order to control and stop the spread of virus. As of now, social distancing is the only recognized way to prevent the spread of the virus. Hence, countries are taking decisions based on their circumstances as well as learning from the experiences of other countries.

Partial or complete lockdown and even imposition of curfew are few of the methods adapted by governments for imposing social distancing.

China, Italy, Spain, France, etc. are among the countries that announced nationwide lockdown. While some countries like Singapore, Russia, Israel, Morocco etc opted for partial lockdown in which they provided space for basic social and economic activities. Few countries such as Dubai, Thailand, Saudi Arabia, Jordan, Kuwait have announced curfew. This curfew is also of two types; (1) 24 hours curfew and (2) curfew in specific hours [7]. Saudi Arabia is among those countries who have curfew in place and most of the major cities have 24 hours curfew. These countries have also stopped religious gathering in orders to prevent the spread of virus [8]. Hence, objectives of the present study were to analyze the (1) partial vs complete lock down effects over the spread of COVID-19, (2) time taken for complete lock down decision in relation with the spread of disease.

\section{Method}

The current observational study was conducted between 14th to 15th April 2020. The study extracted COVID-19 data which was publicly available at "worldometer" [9]. Data was taken up to 14th April 2020 since the beginning of the outbreak. Data was collected for countries which have been affected with the current pandemic. Inclusion criteria for the current study includes (1) countries with more than 1000 COVID-19 cases (2) countries with partial or complete lockdown and (3) known date of imposition of lockdown. List of countries, date and type of lockdown were extracted from "Business Insider" update over coronavirus (6). Hence, there were 29 countries which included in extracted data and analysis.

The variables selected from the data source were; 1) total cases, 2) total deaths, 3) total recovered, 4) number of cases with outcome, 5) number of serious/critical cases, 6) total cases per one million population, 7) total tests performed and 8) total tests performed per one million population. Through more detailed data search additional information was extracted like; date of first case reported, number of cases at the time of lockdown, percentage increase in the number of cases after every week of lockdown, number of deaths at the time of lockdown, percentage increase in the number of deaths after every week of lockdown. Total outcome was calculated by adding total number of deaths and total number of recovered. Percentage death was calculated by using equation "total deaths/total outcome x 100", percentage of recovered cases through "total recovered/total outcome x 100 ", percentage of critical cases 
were obtained through "no. of critical cases/active cases $\times 100$ " and ratio of no. of cases to test performed was done by dividing total number of cases by total number of tests performed.

Statistical package for social sciences (SPSS V.23) was used for data analysis. Descriptive statistics was performed to obtain averages and standard deviations. For inferential statistics, two independent samples T-test were used to compare difference between the averages among the continents. Spearman correlation was performed between the total number of tests performed and total number of cases. Level of significance was set at 0.05 for the current study.

\section{Results}

\section{Effect of partial and complete lockdown on the spread of COVID-19}

Out of 28 countries, 16 announced complete lockdown while 12 opted for partial lockdown. Extracted and computed variables were compared with type of lockdown (partial vs complete). Average differences between the variables were not found statistically significant however, it was observed that percentage of critical cases, ratio between cases to tests performed, cases per million and number of cases at the time of lockdown were higher among complete lockdown countries (Table 1). However, number of weekly reported cases were higher among partially lockdown countries compare. 
Table 1

Effect of type of lockdown over different parameters

\begin{tabular}{|lll|}
\hline Variables & Mean (SE) & \\
\cline { 2 - 3 } & Complete & Partial \\
\hline \% Death & $20.23(5.9)$ & $20.0(6.9)$ \\
\hline \% critical & $3.28(0.7)$ & $2.25(0.7)$ \\
\hline Tests per million & $12.77(3.1)$ & $7.2(1.8)$ \\
\hline Cases per million & $11959(4133.6)$ & $9270.8(2148.5)$ \\
\hline No. of cases at lockdown & $1171.8(296.9)$ & $531.5(173.1)$ \\
\hline No. of cases during 1st of lockdown & $6872.9(2390.3)$ & $8990.6(6972.6)$ \\
\hline No. of cases during 2nd of lockdown & $13431.9(17324.6)$ & $20032.8(15559.6)$ \\
\hline No. of cases during 3rd of lockdown & $19005.4(6225.5)$ & $26859.5(22090.2)$ \\
\hline No. of deaths at lockdown & $495.7(429.0)$ & $27.2(20.8)$ \\
\hline No. of deaths during 1st of lockdown & $873.2(643.5)$ & $146.2(118.7)$ \\
\hline No. of deaths during 2nd of lockdown & $1843.1(1138.9)$ & $556.5(489.9)$ \\
\hline
\end{tabular}

\section{Effect of early decision of complete lockdown on the spread of COVID-19}

\subsection{Number Of Days Taken To Announce Lockdown}

On average, countries took $35.25 \pm 16.6$ days to announce complete lockdown. The least time taken by any country to go for lockdown was 15 days and maximum was 67 days. Number of days taken to announce lockdown had strong, direct and significant correlation with total number of reported cases $(r=$ 0.544 , $p$-value $=0.029)$, number of reported cases when lockdown announced $(r=0.667, p$-value $=0.005)$, number of reported cases during 1 st week $(r=0.67$, p-value $=0.005)$ and 2 nd week $(r=0.733, p$-value $=$ 0.002) of lockdown as well as number of reported deaths when lockdown was announced $(r=0.70$, $p$ value $=0.003$.

\subsection{Early Lockdown In Terms Of Cases}


Average number of reported cases at the time of complete lockdown were $3813( \pm 5521.2)$ and ranged from 72 cases (minimum) to 19848 cases (maximum). Figure 1 shows the number of cases when complete lockdown was imposed in relation to number of cases after every week of lockdown.

Furthermore, the number of reported cases at the time of lockdown announcement was correlated with the other variables, it was found that few variables were strongly and significantly correlated. Cases at lockdown had correlation with no. of cases to test performed $(r=0.57, p$-value $=0.21)$, total present cases $(r=0.868$, $p$-value $=0.000)$, number of cases during 1 st, 2 nd, 3rd weeks of lockdown $(r=0.92, p$-value $=$ $0.000),(0.857, p$-value $=0.000)$ and $(r=0.699, p$-value $=0.011)$ respectively. Similarly, number of reported deaths during 1st week $(r=0.602$, $p$-value $=0.014)$ and 2 nd week $(r=0.613$, $p$-value $=0.015)$ of lockdown was significantly correlated with the number of cases when lockdown was announced.

\section{Discussion}

The current study was designed to evaluate the effect of lockdown over the spread of COVID-19. However, lockdown had its own dimensions which were varying from country to country according to media reports [10]. Some countries have implemented complete and strict lockdown across the nation in which people are only allowed to go out for basic grocery and get medical supplies from their neighborhood and only one person from each family is allowed to go out [11-13]. Whereas, some countries are imposing partial lockdown in which some economical activities are allowed and restrictions to go out are not as tough as those for countries with complete lockdown. Few of the reasons for this partial lockdown could be that these countries belong to middle-low or low-income nations and want to protect their economies. Secondly number of reported cases in these countries are relatively low as compared to some of the European countries.

Comparison of reported data from partial and complete lockdown countries did not prove any significant difference. However, it is important to note down that average number of reported cases at the time of lockdown was lower in partial compare to complete lockdown countries. But average weekly reported cases (after lockdown) was found higher in partial lockdown countries. Difference in cases after first week was 2117.7, after second week 6600.9 and after third week it became 7854.1. By now, difference in weekly reported cases compare to type of lockdown was not statistically significant though comparison was only made up to three weeks. Trend in the difference of weekly reported cases was upwards and it can become significant in the coming weeks.

Another aspect of current study analysis was, how early the step of complete lockdown was taken. This was analyzed in two dimensions, early in terms of days taken after first case was reported and second was the number of reported cases when decision of lockdown was taken. Both these dimensions were found strongly correlated with the progression of virus. Countries who took more than four weeks to announce complete lockdown had very high rate of progression of virus. It showed that the more the time was taken for complete lockdown, the more weekly reported cases of COVID-19 was found. On the other hand, number of reported cases at the time of lockdown also had significant impact on growth of weekly reported cases and deaths after lockdown. 
There were four countries who took early lockdown decision, in terms of time and cases, and their population was more than 30 million. These countries were South Africa, Colombia, Argentina and Kingdom of Saudi Arabia [7]. Among these four countries, Saudi Arabia was the only one who announced partial curfew. Initially the curfew timing was between 5 p.m. to 6 a.m. Later on, curfew timings were increased and currently all major cities have 24 hours curfew. There were some other steps taken by Saudi Arabia that were quite early and significant in order to prevent the spread of virus that included closure of schools within 10 days of first reported COVID-19 case and mosques were closed within 2 weeks [14]. South Africa, Argentina and Colombia were the remaining three countries that had complete lockdown as early as 3 weeks of their first reported case and their number of cases did not exceed from 1000 [7].

Spread of n-CoV was mainly via aerosol transmission, body to body as well as surface to body contactHowever, increase in deaths had some other pre-disposing factors. Strength of human body to fight from the virus was one of the key factors. People with weak immune system or with chronic disease like lung problems, heart disease or diabetes are more prone to get the infection. In the US population, $60 \%$ of adults have at least one of above-mentioned health condition, $40 \%$ have two or more of the above stated health conditions and among which 25 million people are diabetic patients $[15,16]$. Another factor of having high death toll in Spain, Italy, UK and USA in comparison to China could because these countries have the greatest number of lung disease/respiratory disease as reported by NationMaster [17].

\section{Conclusion}

Although number of weekly reported cases for partially lockdown countries were not found significantly higher as compared to countries with complete lockdown countries even though the numbers of cases are higher. Therefore, complete lockdown had an impact in slowing down the progression of n-CoV. Furthermore, early complete lockdown showed that the total number of cases were less than 3300 even after 6 weeks of first case reported. Hence, the number of days taken for lockdown and cases at lockdown announcement had grave impact over the spread of disease.

\section{Declarations}

\section{Ethics approval and consent to participate}

Not Applicable

\section{Consent for publication}

Not Applicable

\section{Availability of data and materials}


1. The main dataset analyzed during the current study is available on Worldometer coronavirus. [Accessed 2020 Apr 14].

Available at https://www.worldometers.info/coronavirus/

\section{Competing interests}

The authors declare that they have no competing interests

\section{Funding}

No Funding

\section{Authors' contributions}

AlHumaid J.: Main Idea, Literature review, article writing, overall supervision

Khan SQ: Main Idea, Literature review, data analysis, article writing, overall supervision

Farooqi FA: Data analysis, article writing and formatting

Alhareky M. Draft Review, Article Writing, Overall supervision

Alonaizan F. Draft Review, Article Writing, Overall supervision

Al Harbi F.: Literature review, article writing, overall supervision

\section{References}

1. CDC: Coronavirus Disease (COVID-19), Situation Sumary. [Accessed 2020, April 14] Available at:https://www.cdc.gov/coronavirus/2019-ncov/cases-updates/summary.html

2. World Health Organization. (2020). Coronavirus disease 2019 (COVID-19): situation report, 85. Aviliable at: https://www.who.int/docs/default-source/coronaviruse/situation-reports/20200414sitrep-85-covid-19.pdf?sfvrsn=7b8629bb_4

3. Abdulamir AS, Hafidh RR. The Possible Immunological Pathways for the Variable Immunopathogenesis of COVID-19 Infections among Healthy Adults, Elderly and Children. Electron J Gen Med. 2020; 17 (4): em202.

4. Dowd JB, Rotondi V, Adriano L, Brazel DM, Block P, Ding X, Liu Y, Mills MC. Demographic science aids in understanding the spread and fatality rates of COVID-19. medRxiv. 2020 Jan 1.

5. World Health Organization. (2020). Questions and answers on coronaviruses [accessed $2020 \mathrm{Apr}$ 11]. Available at: https://www.who.int/news-room/q-a-detail/q-acoronaviruses.

6. World Health Organization. Coronavirus (COVID-19) [accessed 2020 Apr 11].Available At: https://who.sprinklr.com/ 
7. Kaplan J., Frias L., Johnsen M. (Updated 2020, 14 April). A third of the global population is on coronavirus lockdown - here's our constantly updated list of countries and restrictions. Business Insider News. Available At: https://www.businessinsider.com/countries-on-lockdown-coronavirusitaly-2020-3

8. Othman R. (2020, March 24). Saudi Arabia Imposes Lockdown in Capital Riyadh, Two Holy Cities. Bloomberg News. Available at: https://www.bloomberg.com/news/articles/2020-03-25/saudi-arabiaimposes-lockdown-in-capital-riyadh-two-holy-cities [Accessed 2020, April 11]

9. Worldometer coronavirus Cases. [Accessed 2020 Apr 14]. Available At: https://www.worldometers.info/coronavirus/

10. Reality checks Team (2020, April 1). Coronavirus: What measures are countries taking to stop it? BBC News. Available at: https://www.bbc.com/news/world-51737226

11. Johnson T \& Fritz (2020, April 14). You're under a stay-at-home order. [accessed 2000 April 13] Available at: https://www.washingtonpost.com/health/2020/04/06/coronavirus-stay-at-home-bystate/

12. Bhardwa A. (2020, March 24). When and how people can move around in Delhi during coronavirus curfew: [accessed 2020 April 14]Available at: https://theprint.in/india/when-and-how-people-canmove-around-in-delhi-during-coronavirus-curfew/386784/

13. Nafi M. (2020, April 8). Saudi Arabia coronavirus curfew: Ten questions answered. Available at: https://english.alarabiya.net/en/features/2020/04/08/Saudi-Arabia-coronavirus-curfew-Tenquestions-answered

14. Arab News (2020, March 24). King Salman imposes curfew across Saudi Arabia to contain COVID19. Available at: https://arab.news/w8g4s

15. Roni Caryn, Coronavirus Threatens Americans With Underlying Conditions. [Assessed 2020 Apr 11]. Available at https://www.nytimes.com/2020/03/12/health/coronavirus-midlife-conditions.html

16. International Diabetes Federation (IDF) Diabetes Atlas, World Diabetes Congress in Vancouver, Canada (Nov 30-Dec 4). [assessed 2020 Apr 11]. Available at https://endocrinenews.endocrine.org/us-leads-developed-nations-in-diabetes-prevalence/

17. NationMaster statistics database (2020), [last assessed 2020 Apr 11]Available at https://www.nationmaster.com/country-info/stats/Health/Respiratory-disease-deaths

\section{Figures}




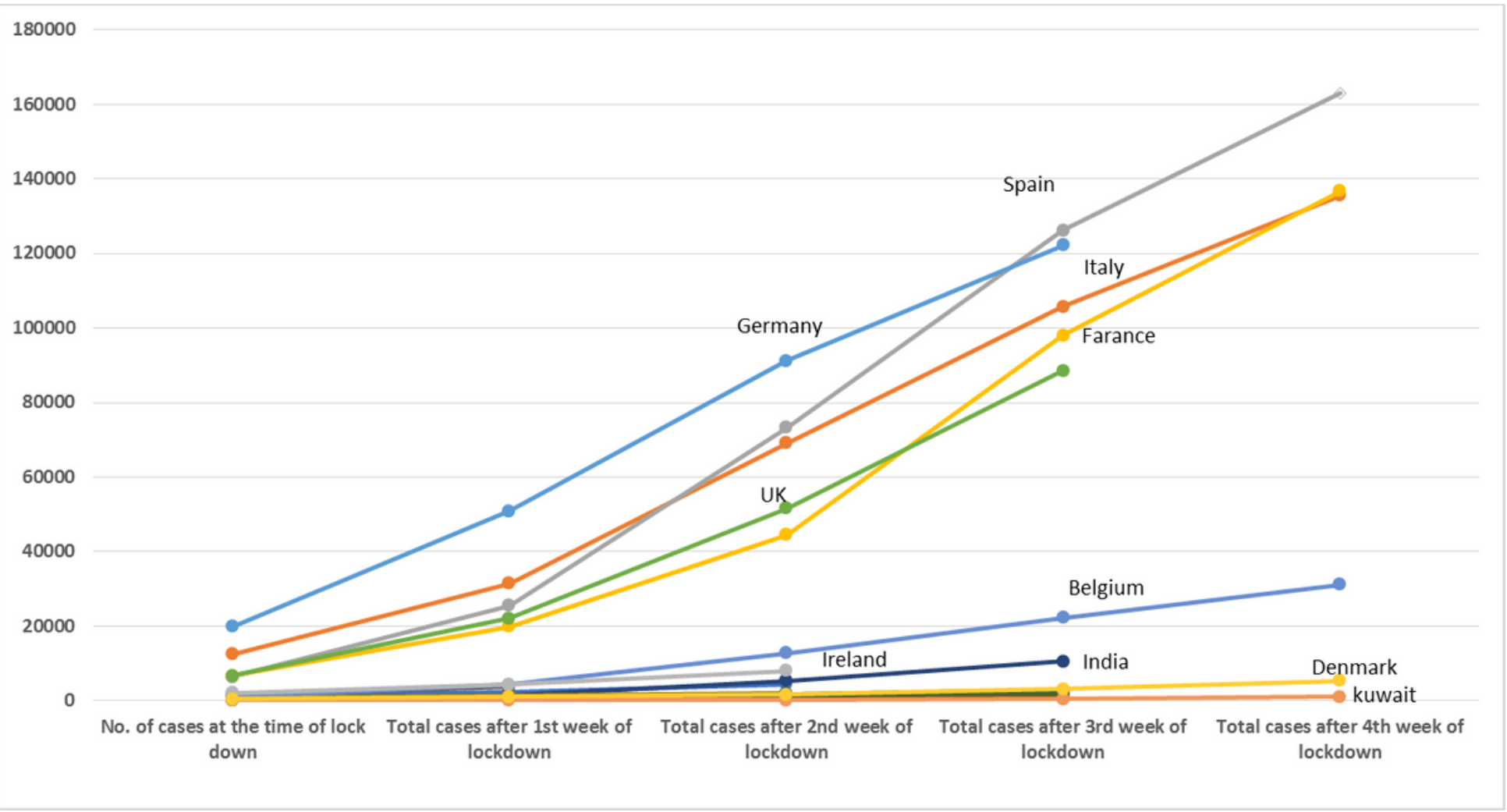

\section{Figure 1}

Number of cases at beginning and after every week of calling complete lockdown in each country 